\section{Case Reports in Neurology}

\title{
Isolated Focal Basilar Artery Stenosis with Acute Stroke Treated with Emergency Thrombectomy and Stenting
}

\author{
Karan Daga ${ }^{a} \quad$ Manish Taneja $^{\mathrm{b}} \quad$ Mohammad Taqueer Ahmad $^{\mathrm{b}}$ \\ Narayanaswamy Venketasubramanian ${ }^{\mathrm{b}}$ \\ ${ }^{a}$ Faculty of Biology, Medicine, and Health, The University of Manchester, Manchester, UK; \\ ${ }^{b}$ Raffles Neuroscience Centre, Raffles Hospital, Singapore, Singapore
}

\section{Keywords}

Basilar artery stenosis $\cdot$ Wingspan stent $\cdot$ Stent $\cdot$ Stroke $\cdot$ Thrombectomy

\begin{abstract}
Strokes due to basilar artery (BA) stenosis/occlusion are devastating. As it is an uncommon cause of stroke, its optimal management is not clearly defined. We present the case of a 68year-old male with a background history of hypertension, hyperlipidaemia, and smoking who developed a sudden onset of reduced consciousness, myoclonic jerks, generalised weakness, and nausea due to an occluded mid-segment BA with right occipital and left cerebellar infarcts. Emergent cerebral angiography was performed and he was immediately treated by clot retrieval and, due to underlying arterial stenosis, the immediate placement of a stent within $3 \mathrm{~h}$ of symptom onset. He had complete neurological recovery within 1 week, with no neurological deficits. He remained well at follow-up 3 months later. Emergency revascularisation of stroke due to BA occlusion should be considered as a treatment option.
\end{abstract}




\section{Case Reports in Neurology}

Case Rep Neurol 2020;12:27-33

\begin{tabular}{l|l}
\hline DOI: 10.1159/000506973 & $\odot 2020$ The Author(s). Published by S. Karger AG, Basel
\end{tabular} www.karger.com/crn

Daga et al.: Emergency Thrombectomy and Stenting for Basilar Artery Stenosis

\section{Introduction}

The posterior cerebral circulation is dependent on one principal vessel: the basilar artery (BA). As it supplies vital structures such as the brainstem, stenosis or acute BA occlusion has a high rate of morbidity and mortality. BA strokes have a significantly worse outcome in comparison to anterior circulation strokes [1]. Prodromal symptoms are non-specific, such as headaches and vertigo [1]. The characteristic symptoms of BA disease include motor and bulbar symptoms: decrease or loss of consciousness, paraesthesia, motor weakness, pupillary and oculomotor symptoms, dysarthria, and dysphagia [1]. Whilst posterior circulation strokes represent one-fifth of all strokes, BA strokes are much more uncommon, causing $<1 \%$ of all strokes $[1,2]$. The medical management for BA stenosis or occlusion, predominantly comprising antiplatelets or anticoagulants such as aspirin, warfarin, and heparin, shows a substantial lack of efficacy [3]. Emergent thrombectomy results in better recanalisation rates and clinical outcomes compared to intravenous or intra-arterial thrombolysis [4]. Transluminal angioplasty and stenting of symptomatic BA stenosis reduces stroke recurrence, clinically relevant restenosis, progression, and death [5]. We report a case of acute stroke due to BA occlusion successfully treated with emergency thrombectomy followed by immediate BA stenting.

\section{Case Report}

A 68-year-old male collapsed while at work and was brought to the emergency department by ambulance. The patient had complained of giddiness with nausea while walking since that morning. Upon examination, he was drowsy. His Glasgow Coma Scale score was 11 and his National Institutes of Health Stroke Scale (NIHSS) score was 15. Both pupils measured $4 \mathrm{~mm}$ and were sluggish. He had no other focal neurological deficits. Myoclonic jerks were then seen in the left lower limb and trunk; he developed loss of consciousness, vomiting, and foaming from the mouth. His NIHSS score fell to 37 and he had to be intubated. He had a history of hypertension, hyperlipidaemia, and smoking. He had had right sensorimotor syndrome secondary to a left middle cerebral artery infarct 2 years before.

Urgent computed tomography of the head did not reveal any acute abnormality. Magnetic resonance imaging showed acute right occipital infarct and a left cerebellar infarct (Fig. 1). Time-of-flight magnetic resonance angiogram showed occlusion of the BA (Fig. 2). He was diagnosed as having an acute ischaemic stroke with clots in the posterior cerebral circulation. Intravenous thrombolysis was offered but declined by the family.

An emergency cerebral angiogram was done. There was complete occlusion of the BA with no flow identified distally; the vertebral arteries were patent. No flow was seen through the posterior communicating artery either. A 6-Fr envoy guiding catheter (Codman) was placed in the right vertebral artery. The occluded segment was crossed using an SL-10 microcatheter (Stryker) with a Synchro ( 0.014 inch, Stryker) to cross the occlusion followed by clot removal using a TREVO 4 by $20 \mathrm{~mm}$ stent retriever device (Stryker). The clot was removed successfully. Severe underlying focal stenosis in the mid-BA was seen. The flow was slow as demonstrated over serial repeat angiograms over a period of $5 \mathrm{~min}$ post clot removal. It was decided to proceed with stent placement to prevent re-occlusion and re-thrombosis of the BA. The diseased mid-basilar segment was treated with a 3 by $15 \mathrm{~mm}$ Wingspan stent (Stryker). Completion angiogram showed complete re-establishment of flow with a revascularized BA and its distal branches (Fig. 3). After the anaesthesia had worn off, the patient's NIHSS score

\section{Karger'=}




\section{Case Reports in Neurology}

Case Rep Neurol 2020;12:27-33

\begin{tabular}{l|l}
\hline DOI: $10.1159 / 000506973$ & (c) 2020 The Author(s). Published by S. Karger AG, Basel
\end{tabular} www.karger.com/crn

Daga et al.: Emergency Thrombectomy and Stenting for Basilar Artery Stenosis

was 3, with mild dysarthria and limb weakness. He recovered completely over the subsequent days and was discharged after 7 days in hospital with an NIHSS score of 0. Follow-up at 3 months showed no residual deficit with complete recovery. Repeat magnetic resonance imaging showed complete resolution of the cerebral infarcts with patent flow in the treated BA.

\section{Discussion}

BA strokes account for merely $3 \%$ of all ischaemic strokes and are not as well described in the literature as anterior circulation strokes [6]. The treatment options for BA stenosis range from medical anticoagulant therapy to endovascular stenting or balloon angioplasty to neurosurgical approaches such as bypass grafting for the BA.

The principal advantage of medical therapy is that it is non-invasive, and as such it is a safer option. The SAMMPRIS trial [7] investigated a cohort of 451 patients with 70-99\% intracranial artery stenosis treated with medical management either alone or in combination with percutaneous transluminal angioplasty and stenting using a Wingspan stent. The authors reported a 30-day stroke or mortality rate of 14.7 and 5.8\% in the percutaneous transluminal angioplasty and stenting and medical management groups, respectively. Based on this disparity, they concluded that medical management alone is the superior choice of treatment.

However, there have been studies of medical therapy for isolated basilar or vertebrobasilar artery stenosis that show a substantial lack of efficacy. The Warfarin-Aspirin Symptomatic Intracranial Disease (WASID) group compared the safety and efficacy of the two anticoagulants in a multicentric post hoc analysis of 68 patients with a stroke secondary to a 50-99\% stenotic BA [3]. They found that $23 \%$ of patients taking aspirin had a subsequent stroke in the same vascular territory as the stenotic artery and $10 \%$ for warfarin. The WASID group concluded that their findings of the high rate of subsequent strokes in the stenotic territories suggest that endovascular therapy may be needed for symptomatic severe stenosis of the vertebrobasilar circulation. Given the severity of an ischaemic BA, it is imperative to employ alternative treatment options which are more effective in the long term.

Medical therapy, such as statins and antihypertensives, should be considered for the longterm secondary prevention of stroke. In a retrospective study of 153 patients with symptomatic BA stenosis, Yum et al. [8] reported a much lower stroke recurrence of $14.9 \%$ for patients taking statins, compared to $35.9 \%$ in those that did not. They also reported progression of the BA stenosis in $7.0 \%$ of patients in the statin group compared to $28.2 \%$ in the non-statin group.

Acute recanalisation was achieved in our patient by emergency thrombectomy using a stent retriever. Arterial recanalisation by stent retrievers has been described extensively in the literature for anterior circulation strokes. However, fewer studies have demonstrated their safety and efficacy in BA strokes. Shu et al. [9] proposed that mechanical thrombectomy has a greater efficacy than intravenous thrombolysis. In a review including 672 patients, they reported a higher recanalisation rate in patients treated with stent retriever thrombectomy $(88 \%)$ than those treated with intravenous thrombolysis $(60 \%)$ and a lower mortality rate: 26 and $41 \%$, respectively. When considering endovascular treatment for cerebrovascular abnormalities, the effect of reperfusion injury must be considered. In the case of the posterior cerebral circulation, rapid revascularisation carries a relatively low risk. Guillaume et al. [10] found $40 \%$ of a cohort of 90 patients to have a positive outcome from reperfusion of an

\section{Karger'=}




\section{Case Reports in Neurology}

Case Rep Neurol 2020;12:27-33

\begin{tabular}{l|l}
\hline DOI: 10.1159/000506973 & $\odot 2020$ The Author(s). Published by S. Karger AG, Basel
\end{tabular} www.karger.com/crn

Daga et al.: Emergency Thrombectomy and Stenting for Basilar Artery Stenosis

occluded BA, concluding that rapid endovascular reperfusion should occur immediately after imaging.

The placement of stents for BA stenosis or occlusion could be considered as a first-line treatment. For our patient, we used two overlaying, self-expanding Wingspan stents (Stryker) to re-establish flow and vessel patency. Several studies have investigated the use of stents. In a cohort of 100 patients, Jiang et al. [11] reported a 99\% success rate with Wingspan stent placement and a risk of adverse outcomes by 12 months of 7.3\%, which was much lower than for similar WASID patients [3]. It should be noted that this was a study on intracranial stenosis, not specific to the BA. However, whilst posterior circulation strokes are known to have high morbidity and mortality, there have been other studies demonstrating similar results. Wolfe et al. [12] studied the use of Wingspan stents in 51 patients with $50-99 \%$ stenosis of the BA. They concluded that these stents resulted in only one event of stroke or death after the first 30 days $(2.0 \%)$, which indicated a good long-term efficacy. In a retrospective study of 213 patients with severe stenosis of the vertebrobasilar artery, Zhou et al. [13] reported successful revascularisation in $98.6 \%$ of patients. They found the stenosis to reduce from $86.3 \pm 6.8 \%$ to $9.1 \pm 3.7 \%$ after placement of a stent. These results encourage the use of stents for secondary prevention.

In the acute setting, the combined approach of emergency thrombectomy and stent placement may be the most appropriate. Siebert et al. [14] and Behme et al. [15] have shown results in favour of similar methods, with several patients achieving Thrombolysis in Cerebral Infarction (TICI) scores of $2 \mathrm{~b}$ and 3. Siebert et al. [14] performed mechanical thrombectomy in 39 patients, of which $84.2 \%$ were with stent retrievers. In $52.6 \%$ of patients, additional stent angioplasty was performed and successful reperfusion (TICI $2 \mathrm{~b}-3$ ) was achieved in $86.8 \%$ of cases. Siebert et al. [14] found an equal in-hospital mortality rate with the stent and non-stent angioplasty groups $(n=7)$. Behme et al. [15] presented a series of 7 patients who underwent stenting for high-grade BA stenosis, 6 of whom also received mechanical thrombectomy. They reported successful recanalisation (TICI $2 \mathrm{~b}-3$ ) in all patients and one in-hospital death. They concluded that this combination of thrombectomy and stenting may be appropriate in the rare cases of high-grade BA stenosis which are acutely occluded.

The use of stents carries some limitations. The risks and complications associated with this treatment options include periprocedural risks of ischaemia, haemorrhage, intimal dissection, postoperative neurological deficits, and the possibility of in-stent restenosis $[5,7,11$, 12]. Additionally, another periprocedural risk is BA branch occlusion due to the "snowploughing" effect (displacing plaque into branch/perforating arteries during the process of stent deployment) in branches such as the anterior inferior cerebellar artery or the pontine arteries. However, as shown in Figure 3, the opacification of the right anterior inferior cerebellar artery demonstrates established blood flow in our patient, despite its origin being covered by the stent.

In conclusion, BA stenosis is a critical disease and urgent intervention is often required. The current literature on BA strokes is limited and management options are still debated. Complete recovery is possible if it is treated in a timely manner. In the case we present, emergency stent placement was the first-line treatment to maintain patency of the underlying diseased vessel.

\section{Karger'=}




\section{Case Reports in Neurology}

\section{Acknowledgements}

We would like to thank the patient mentioned in this paper for his help and contribution.

\section{Statement of Ethics}

Informed consent was given by the patient for publication of this report and the figures included. This study was conducted ethically, in accordance with the Helsinki Declaration.

\section{Conflict of Interest Statement}

The authors have no conflicts of interest to declare.

\section{Funding Sources}

The authors have no funding sources to disclose.

\section{Author Contributions}

K. Daga performed the literature search and prepared the manuscript. M. Taneja was the radiologist who diagnosed and treated the patient, provided the figures, and helped prepare the manuscript. M.T. Ahmad was the neurologist responsible for the care of the patient and revised the manuscript. $\mathrm{N}$. Venketasubramanian was involved in preparing and revising the manuscript.

\section{References}

1 Mattle HP, Arnold M, Lindsberg PJ, Schonewille WJ, Schroth G. Basilar artery occlusion. Lancet Neurol. 2011 Nov;10(11):1002-14.

2 Israeli-Korn SD, Schwammenthal Y, Yonash-Kimchi T, Bakon M, Tsabari R, Orion D, et al. Ischemic stroke due to acute basilar artery occlusion: proportion and outcomes. Isr Med Assoc J. 2010 Nov;12(11):671-5.

3 Prognosis of patients with symptomatic vertebral or basilar artery stenosis. The Warfarin-Aspirin Symptomatic Intracranial Disease (WASID) Study Group. Stroke. 1998 Jul;29(7):1389-92.

4 Sheng K, Tong M. Therapy for acute basilar artery occlusion: a systematic review and meta-analysis. F1000Res. 2019 Feb;8:165.

5 Maier IL, Karch A, Lipke C, Behme D, Mpotsaris A, Kabbasch C, et al. Transluminal angioplasty and stenting versus conservative treatment in patients with symptomatic basilar artery stenosis: perspective for future clinical trials. Clin Neuroradiol. 2018 Mar;28(1):33-8.

6 Weimar C, Goertler M, Harms L, Diener HC. Distribution and outcome of symptomatic stenoses and occlusions in patients with acute cerebral ischemia. Arch Neurol. 2006 Sep;63(9):1287-91.

7 Chimowitz MI, Lynn MJ, Derdeyn CP, Turan TN, Fiorella D, Lane BF, et al.; SAMMPRIS Trial Investigators. Stenting versus aggressive medical therapy for intracranial arterial stenosis. N Engl J Med. 2011 Sep; 365(11):993-1003.

8 Yum KS, Chang JY, Jeong WJ, Lee S, Jeong JH, Yeo MJ, et al. Effect of statin on progression of symptomatic basilar artery stenosis and subsequent ischemic stroke. PLoS One. 2017 Oct;12(10):e0183798.

\section{Karger'=}




\section{Case Reports in Neurology}

\begin{tabular}{l|l}
\hline DOI: $10.1159 / 000506973$ & $\begin{array}{l}\text { ( ) 2020 The Author(s). Published by S. Karger AG, Basel } \\
\text { www.karger.com/crn }\end{array}$ \\
\hline
\end{tabular}

Daga et al.: Emergency Thrombectomy and Stenting for Basilar Artery Stenosis

9 Shu L, Salehi Ravesh M, Jansen O, Jensen-Kondering U. Stent Retriever Thrombectomy Potentially Increases the Recanalization Rate, Improves Clinical Outcome, and Decreases Mortality in Acute Basilar Occlusion: A Systematic Review and Meta-Analysis. Cerebrovasc Dis Extra. 2019;9(2):46-56.

10 Guillaume M, Lapergue B, Gory B, Labreuche J, Consoli A, Mione G, et al.; Endovascular Treatment in Ischemic Stroke (ETIS) Investigators. Rapid successful reperfusion of basilar artery occlusion strokes with pretreatment diffusion-weighted imaging posterior-circulation ASPECTS $<8$ is associated with good outcome. J Am Heart Assoc. 2019 May;8(10):e010962.

11 Jiang WJ, Yu W, Du B, Gao F, Cui LY. Outcome of patients with $\geq 70 \%$ symptomatic intracranial stenosis after Wingspan stenting. Stroke. 2011 Jul;42(7):1971-5.

12 Wolfe TJ, Fitzsimmons BF, Hussain SI, Lynch JR, Zaidat OO. Long term clinical and angiographic outcomes with the Wingspan stent for treatment of symptomatic 50-99\% intracranial atherosclerosis: single center experience in 51 cases. J Neurointerv Surg. 2009 Jul;1(1):40-3.

13 Zhou Y, Wang L, Zhang JR, Zhou K, Shuai J, Gong ZL, et al. Angioplasty and stenting for severe symptomatic atherosclerotic stenosis of intracranial vertebrobasilar artery. J Clin Neurosci. 2019 May;63:17-21.

14 Siebert E, Bohner G, Zweynert S, Maus V, Mpotsaris A, Liebig T, et al. Revascularization Techniques for Acute Basilar Artery Occlusion: Technical Considerations and Outcome in the Setting of Severe Posterior Circulation Steno-Occlusive Disease. Clin Neuroradiol. 2019 Sep;29(3):435-43.

15 Behme D, Weber W, Mpotsaris A. Acute basilar artery occlusion with underlying high-grade basilar artery stenosis: multimodal endovascular therapy in a series of seven patients. Clin Neuroradiol. 2015 Sep;25(3): 267-74.
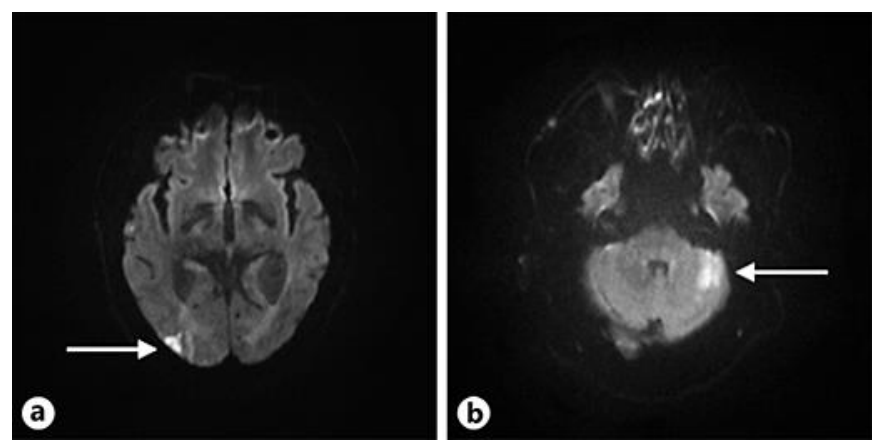

Fig. 1. Magnetic resonance imaging diffusion-weighted imaging showing an acute right occipital infarct (a) and a left cerebellar infarct (b). 
Case Reports in Neurology
Case Rep Neurol 2020;12:27-33

DOI: 10.1159/000506973

(c) 2020 The Author(s). Published by S. Karger AG, Basel www.karger.com/crn
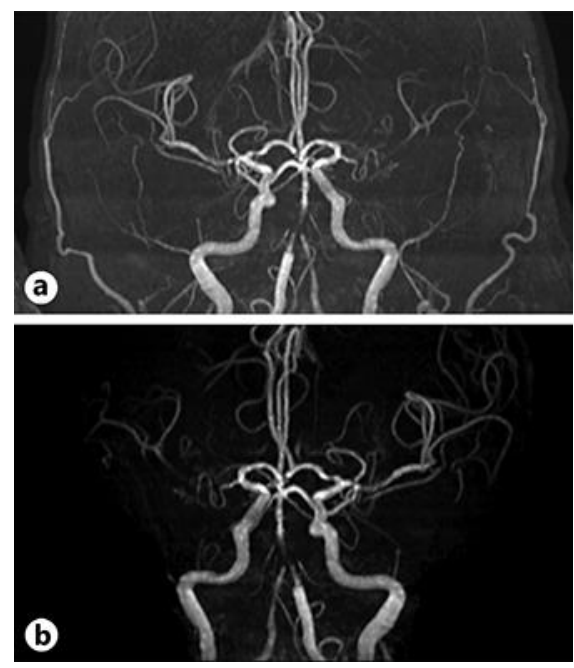

Fig. 2. Magnetic resonance angiogram showing pre-procedure occlusion of the basilar artery with minimal flow in both vertebral arteries (a) and post-procedure patent vertebral and basilar arteries with metallic artefact from stents (b).

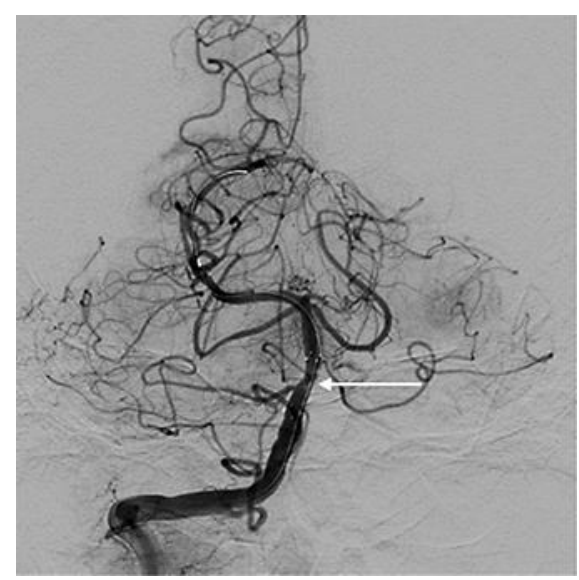

Fig. 3. Catheter angiogram post clot retrieval and stent deployment showing a patent basilar artery and restored posterior cerebral blood flow. 